\title{
O desafio diagnóstico de uma zoonose
}

Susana Silva Pinto, ${ }^{1}$ Raquel Aires Pereira, Ana Luísa Graça, Cátia Caldas, António Sarmento

\section{RESUMO}

Introdução: A febre Q é uma zoonose, causada pela Coxiella burnetii. Esta bactéria está presente em produtos de animais, sobretudo gado ovino, caprino e bovino e transmite-se ao humano pela inalação de aerossóis. Sendo uma doença de declaração obrigatória em Portugal desde 1999, é epidemiologicamente relevante em todo o mundo, tanto na sua forma aguda, com relato de vários surtos na última década, como na sua forma persistente localizada, sendo das causas mais comum de endocardite com hemoculturas negativas.

Descrição do caso: Mulher de 47 anos que se dirige aos cuidados de saúde primários com febre prolongada, sem foco evidente, após assistir a um parto de gado caprino, tendo sido referenciada ao serviço de urgência hospitalar. Pela apresentação clínica, corroboração analítica e epidemiologia fortemente sugestiva, iniciou terapêutica empírica para brucelose com doxiciclina e estreptomicina. Posteriormente, na consulta externa de infeciologia, foi confirmado diagnóstico de febre $\mathrm{Q}$ e ajustada terapêutica. A doente completou 14 dias de tratamento com doxiciclina, com melhoria clínica e sem complicações.

Comentário: Doentes com febre Q podem apresentar-se com um amplo espectro de manifestações da doença: ausência de sintomas, sintomas ligeiros a graves, bem como doença persistente localizada. Devido à inespecificidade dos sinais e sintomas da febre Q, o diagnóstico laboratorial é essencial para a confirmação da suspeita clínica. Relativamente ao tratamento, a doxiciclina é o antibiótico de primeira linha para o tratamento desta infeção. Este caso clínico mostra que a acessibilidade dos cuidados de saúde primários na atualidade promove o primeiro ponto de contacto com o Serviço Nacional de Saúde e o papel do médico de família enquanto responsável pela articulação com outras especialidades.

Palavras-chave: Zoonose; Febre Q; Cuidados de saúde primários.

\section{INTRODUÇÃO}

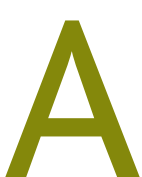

febre Q é uma zoonose causada pela Coxiella burnetii, um bacilo de gram negativo intracelular estrito. Esta bactéria é transmitida ao homem através de aerossóis contaminados por produtos (fezes, urina, leite, produtos de parto) de animais infetados: ovinos, caprinos e bovinos, predominantemente. ${ }^{1}$

A sua distribuição é mundial e com crescente interesse na Europa, tanto na sua forma aguda, com relato de vários surtos na última década, como na sua forma persistente localizada, sendo das causas mais comuns de endocardite com hemoculturas negativas. ${ }^{2}$

Como noutros países europeus com características edafoclimáticas, ecológicas e pecuárias semelhantes às de Portugal, esta infeção é um problema de saúde pública, sendo uma doença de declaração obrigatória desde $1999 .^{3}$

1. ACeS Grande Porto I, USF Ponte Velha
A febre Q pode manifestar-se tanto na forma aguda, como na forma crónica ou persistente localizada., ${ }^{1,-5}$ Após um período de incubação de cerca de 2-3 semanas, a infeção aguda pode ser assintomática ou manifestar-se por uma síndroma febril inespecífica, pneumonia ou hepatite. Na maioria dos casos, o prognóstico é benigno e a sintomatologia resolve espontaneamente. A gravidez constitui um fator de risco para complicações da doença, mesmo na forma aguda, com maior risco de abortamento, parto pré-termo e baixo peso do recém-nascido. ${ }^{1}$

A principal morbimortalidade associada a esta doença, na sua forma crónica, está relacionada com a infeção endovascular - particularmente a endocardite que ocorre meses a anos após a infeção inicial, podendo não ser precedida de sintomas na fase aguda. Os doentes com próteses endovasculares estão em particular risco de evolução para a forma crónica. ${ }^{1}$

Este artigo relata o caso clínico de uma zoonose e tem como principal objetivo sensibilizar os médicos de 


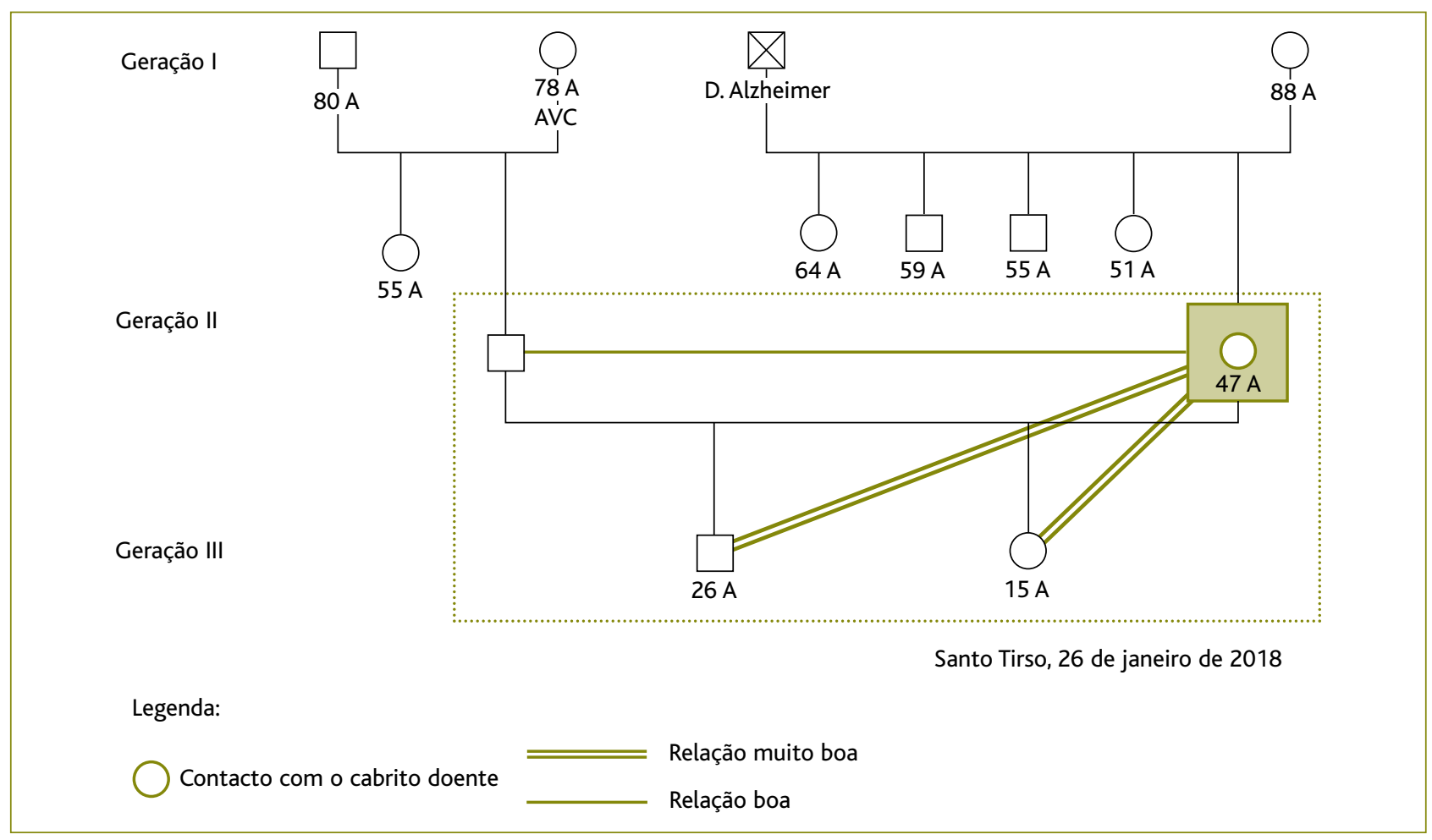

Figura 1. Genograma e psicofigura de Mitchel.

família para a forma de apresentação de uma patologia rara, bem como destacar a importância da articulação dos cuidados de saúde primários e secundários.

\section{DESCRIÇÃO DO CASO}

Mulher de 47 anos, casada, raça caucasiana, gerente de posto de abastecimento de combustível em sociedade com o marido. Insere-se numa família nuclear altamente funcional, na fase VI do Ciclo de Duvall e do ponto de vista socioeconómico pertence à classe média de Graffar. O genograma indica-nos um agregado familiar de quatro elementos (Figura 1).

Habita numa zona de transição rural, em moradia com quintal e animais de estimação (gatos e cães) e faz criação de gado caprino, com acompanhamento veterinário. Refere consumo de produtos alimentares de confeção artesanal (como queijos e chouriços) e de água engarrafada ou da companhia. Não fez qualquer viagem recente.

Como antecedentes médico-cirúrgicos de referir doença de refluxo gastroesofágico, tendo realizado fundoplicatura de Nissen, três anos antes, estando medi- cada com inibidor da bomba de protões. Não tem doença cardiovascular conhecida, nem próteses endovasculares nem lhe é conhecida causa de imunossupressão.

Duas semanas antes do início do quadro assistiu ao parto de cabritos e uma das crias estaria doente, tendo sido observado pelo veterinário e colocada a hipótese diagnóstica de brucelose. A doente e o seu marido trataram do animal doente, administrando medicação diariamente.

Recorreu à consulta não programada da sua Unidade de Saúde Familiar (USF) por quadro de 10 dias de evolução de febre / subfebril (temperatura axilar máxima de $38,1^{\circ} \mathrm{C}$ ), associada a astenia marcada, prostração, hipersudorese, artralgias simétricas intensas, náuseas e diarreia. Negava outros sintomas, nomeadamente neurológicos, respiratórios, dor abdominal ou queixas genito-urinárias. O marido estaria com sintomas semelhantes.

Ao exame objetivo apresentava: mucosas hidratadas e ligeiramente descoradas; temperatura auricular $37,4^{\circ} \mathrm{C}$; sem sinais de dificuldade respiratória; saturação 
de oxigénio, em ar ambiente, 99\%; pressão arterial 117/82mmHg; frequência cardíaca de 70 batimentos por minuto; auscultação cardiopulmonar e abdómen sem alterações de relevo. Sem sinais inflamatórios ao nível das articulações dos cotovelos, punhos, mãos, joelhos, tornozelos e pés.

Atendendo ao contexto epidemiológico, a doente foi referenciada para o serviço de urgência do Centro Hospitalar Universitário de São João, para observação por infeciologia pela suspeita de zoonose.

O estudo analítico realizado revelou: leucopenia (leucócitos 2,58 x 10,9/L) e trombocitopenia (plaquetas $116 \times 10,9 / \mathrm{L}$ ); transaminases, gama-GT e fosfatase alcalina normais; creatinina e ureia com valores normais e elevação da proteína C reativa $(35 \mathrm{mg} / \mathrm{L})$. A serologia de VIH foi negativa. A radiografia de tórax e a ecografia abdominal e renopélvica não revelaram alterações. Colheu hemoculturas e para avaliação de agentes zoonóticos foram solicitadas as seguintes serologias: Borrelia (burgdorferi, garinii, afzelii), Coxiella burnetti, Ricketsia conorii e reação de Wright e Widal.

Pela apresentação clínica, corroboração analítica e epidemiologia fortemente sugestiva iniciou terapêutica empírica para brucelose com doxiciclina e estreptomicina.

Do estudo serológico efetuado no serviço de urgência verificou-se positividade para a serologia de Coxiella burnetii (teste Micro-Elisa - para deteção de IgG e IgM fase II): IgM positivo e IgG negativo. As restantes serologias foram negativas, assim como as hemoculturas. A reação em cadeia da polimerase (PCR) para pesquisa de Coxiella burnetii no sangue, ao décimo quinto dia de sintomas e já sob antibioterapia (terceiro dia), foi negativa. Após conhecimento do resultado serológico, o esquema terapêutico foi ajustado, com suspensão da estreptomicina e continuação do tratamento com doxiciclina, tendo completado 14 dias de tratamento, com melhoria clínica e sem complicações, ficando assintomática na reavaliação clínica ao primeiro mês.

A doente realizou ecocardiograma que excluiu patologia cardíaca valvular. O estudo serológico realizado quatro semanas após revelou IgM duvidoso e IgG negativo. Ao terceiro mês pós tratamento, a serologia foi negativa (IgG e IgM), assim como ao sexto mês.

Foi realizada notificação da doença no Sistema Nacional de Vigilância Epidemiológica (SINAVE). A uni- dade de saúde pública realizou visita domiciliária para concluir o inquérito epidemiológico, tendo constatado um rebanho doméstico de oito caprinos. Os animais foram alvo de rastreio serológico da febre Q e outras zoonoses pela medicina veterinária, cujos resultados se revelaram negativos. Foi colocada a hipótese de contágio da doença a partir de exploração agrícola vizinha. Foi realizado ensino de cuidados a ter no contacto com o gado caprino doméstico, consumo de leite e derivados lácteos não pasteurizados, assim como no contacto com eventuais explorações agrícolas na vizinhança.

Apesar de o marido referir sintomatologia semelhante à doente em análise, não se confirmou a suspeita clínica, sendo excluída a infeção por Coxiella burnetii através de serologia e biologia molecular no sangue.

\section{COMENTÁRIO}

A Coxiella burnetiié um cocobacilo intracelular pleomórfico, responsável pela febre Q. Estudos moleculares classificaram-no como filo Proteobacteria, da mesma ordem da Legionella spp. ${ }^{4}$

Vários animais são reservatórios deste agente, sendo que a maioria não apresenta sintomas; a doença manifesta-se clinicamente na espécie humana. É no contacto com o gado bovino, ovino e caprino que reside o maior risco de infeção. Estes animais eliminam a bactéria, em grande quantidade, nas fezes, na urina e no leite, que é uma fonte de infeção humana quando é consumido sem a pasteurização UHT (Ultra-High Temperature). No momento do parto ou eventual aborto é expelida uma grande quantidade de partículas infeciosas, nomeadamente no líquido amniótico, placenta e membranas fetais. A principal via de contágio estabelece-se através da inalação de partículas aerossóis, que podem percorrer longa distâncias. A infeção também pode ocorrer por via sexual e transmissão vertical. ${ }^{1}$

Doentes com febre Q podem apresentar-se com um amplo espectro de manifestações da doença: ausência de sintomas, sintomas ligeiros a graves, bem como doença persistente localizada. ${ }^{4-5}$

O período de incubação da infeção aguda é, em média, de vinte dias (14-39 dias). A síndroma gripal é a manifestação mais comum, que pode incluir febre alta associada a fadiga, cefaleias e mialgias. ${ }^{4,6}$ Pode manifestar-se também como pneumonia, hepatite e/ou endocardite aguda. A gravidade da maioria dos casos de 
pneumonia por febre Q é ligeira e os doentes apresentam febre com tosse sem expetoração, dor pleurítica, anorexia, mialgias e artralgias. Os achados na radiografia de tórax não são específicos. Pode ocorrer derrame pleural, mas é uma apresentação incomum. ${ }^{1}$ Os doentes com hepatite apresentam padrão de citólise com hepatomegalia, geralmente sem icterícia, acompanhado por febre. Este quadro é acompanhado, por vezes, de dor abdominal (especialmente no hipocôndrio direito), anorexia, vómitos, diarreia e náuseas. ${ }^{7} \mathrm{Al}-$ guns doentes com febre $\mathrm{Q}$ aguda podem desenvolver endocardite aguda, que parece ser uma complicação autoimune da infeção precoce associada à síndroma antifosfolipídica. ${ }^{8}$

A doença crónica ou persistente localizada geralmente instala-se no período de seis meses a um ano após a infeção, podendo surgir até cerca de vinte anos após a infeção inicial. A sintomatologia na forma aguda não prediz o desenvolvimento de doença crónica. ${ }^{1}$

Os doentes com valvulopatias, próteses valvulares e articulares, grávidas e imunodeprimidos (transplantados, hemodialisados, doentes com neoplasias e VIH), apresentam maior risco de complicações da doença. ${ }^{1}$

A doença endovascular é a manifestação mais comum e grave da forma persistente localizada. ${ }^{1}$ Doentes com valvulopatia prévia apresentam alto risco de desenvolver endocardite crónica secundária a Coxiella burnetti, que é a doença mais comum na infeção crónica. Pode ocorrer também infeção vascular, num aneurisma ou prótese vascular. Também estão descritos casos de osteomielite, com exame cultural negativo, e/ou infeção da prótese articular causados por Coxiella burnetti. $^{4-5}$

Devido à inespecificidade dos sinais e sintomas da febre Q, o diagnóstico laboratorial é essencial para a confirmação da suspeita clínica. ${ }^{2,4-5} \mathrm{~A}$ deteção de anticorpos de fase II, na forma aguda, e de fase I, na forma crónica, suportam o diagnóstico. No entanto, nas fases mais precoces da doença a serologia pode ainda não ser positiva e nestes casos o diagnóstico, pode ser confirmado pela deteção de Coxiella burnetii no sangue ou tecidos por técnicas de biologia molecular. A cultura está reservada a laboratórios de referência.

Relativamente ao tratamento, a doxiciclina é o antibiótico de primeira linha para o tratamento da infeção aguda, na posologia de 100mg de 12 em 12 horas em adultos ou crianças com peso superior a $45 \mathrm{~kg}$ ou $2,2 \mathrm{mg} / \mathrm{kg} / \mathrm{dia}$ em crianças com peso inferior a $45 \mathrm{~kg}$ (dose máxima de 200mg por dia) durante 14 dias. O seu uso é contraindicado em crianças com idade inferior a oito anos e em grávidas. Se a doença for grave (gravidade da doença aguda ou fatores de risco para endocardite), as crianças, mesmo com menos de oito anos, devem fazer doxiciclina. ${ }^{1,9}$

Nas crianças com idade inferior a oito anos, sem critérios de gravidade, recomenda-se o tratamento com cotrimoxazol. Para a gestão da terapêutica nas grávidas deve solicitar-se o apoio das especialidades de infeciologia e obstetrícia.

Segundo a definição europeia de medicina geral e familiar da WONCA, o médico de família é "o primeiro ponto de contacto médico com o sistema de saúde" e "utiliza de forma eficiente os recursos de saúde através da coordenação de cuidados, através do trabalho com outros profissionais no contexto dos Cuidados de Saúde Primários, bem como através da gestão da interface com outras especialidades". ${ }^{109}$ De facto, este caso clínico mostra que a acessibilidade dos cuidados de saúde primários na atualidade promove o primeiro ponto de contacto com o Serviço Nacional de Saúde e o papel do médico de família, enquanto responsável pela articulação com outras especialidades. O diagnóstico de suspeição de uma zoonose é um desafio para o médico de família, tendo em conta o curto período de tempo (10 minutos) de uma consulta não programada. No entanto, a colheita de uma anamnese com contexto epidemiológico, associada a uma boa colaboração da doente, foram essenciais para a referenciação da doente para o serviço de urgência de um centro hospitalar do grupo III, com a possibilidade de avaliação por especialidade de infeciologia em contexto de urgência, contribuindo assim para a melhor orientação deste caso.

\section{REFERÊNCIAS BIBLIOGRÁFICAS}

1. Anderson A, Bijlmer H, Fournier PE, Graves S, Hartzell J, Kersh GJ, et al. Diagnosis and management of Q fever — United States, 2013: recommendations from CDC and the Q Fever Working Group. MMWR. 2013;62(3):1-23.

2. Santos AS, Bacellar F, França A. Febre Q: revisão de conceitos [Q fever: a revision of concepts]. Rev Port Med Interna. 2007;14(2):90-9. Portuguese

3. Santos AS. Febre Q: do diagnóstico à investigação ecoepidemiológica de Coxiella burnetii no contexto da infeção humana. Bol Epidemiológico INSA. 2015;4(14):20-4. 
4. Parreira PA. Estudo da prevalência de anticorpos anti Coxiella burnetii numa amostra de dadores de sangue de uma região portuguesa [dissertation]. Lisboa: Faculdade de Medicina da Universidade de Lisboa; 2008.

5. Hartzell JD, Wood-Morris RN, Martinez LJ, Trotta RF. Q fever: epidemiology, diagnosis, and treatment. Mayo Clin Proc. 2008;83(5):574-9.

6. Dupuis G, Petite J, Péter O, Vouilloz M. An important outbreak of human Q fever in a Swiss Alpine valley. Int J Epidemiol. 1987;16(2):282-7.

7. Fournier PE, Marrie TJ, Raoult D. Diagnosis of Q fever. J Clin Microbiol. 1998;36(7):1823-34.

8. Million M, Thuny F, Bardin N, Angelakis E, Edouard S, Bessis S, et al. Antiphospholipid antibody syndrome with valvular vegetations in acute Q fever. Clin Infect Dis. 2016;62(5):537-44.

9. Gikas A, Spyridaki I, Scoulica E, Psaroulaki A, Tselentis Y. In vitro susceptibility of Coxiella burnetii to linezolid in comparison with its susceptibilities to quinolones, doxycycline, and clarithromycin. Antimicrob Agents Chemother. 2001;45(11):3276-8.

10. WONCA Europa. A definição europeia de medicina geral e familiar
(Clínica geral / Medicina familiar). WONCA Europa; 2002. Available from: https://www.woncaeurope.org/file/b662cccc-6ad6-4d34-a9a2fd02d29fae5b/European\%20Definition\%20in\%20Portuguese.pdf

\section{CONFLITO DE INTERESSES}

Os autores declaram não ter quaisquer conflitos de interesse.

\section{FINANCIAMENTO}

O trabalho relatado neste manuscrito não foi objeto de qualquer tipo de financiamento externo (incluindo bolsas e investigação).

\section{ENDEREÇO PARA CORRESPONDÊNCIA}

Susana Silva Pinto

E-mail: susyapinto@gmail.com

https://orcid.org/0000-0001-9764-6251

Recebido em 23-05-2019

Aceite para publicação em 03-10-2019

\section{ABSTRACT}

\section{THE DIAGNOSTIC CHALLENGE OF A ZOONOSIS}

Introduction: Q fever is a zoonosis, caused by Coxiella burnetii. This bacterium is present in animal products, especially sheep, goats and cattle and is transmitted to the human by inhalation of aerosols. Being a notifiable disease in Portugal since 1999, it is epidemiologically relevant all over the world, both in its acute form, with reports of several outbreaks in the last decade, and in its persistent localized form, being the most common cause of endocarditis with blood cultures negative.

Case description: A 47-year-old woman who goes to primary health care with prolonged fever without evident focus, after attending a goat's delivery, was referred to the hospital emergency service. Due to the clinical presentation, analytical corroboration, and highly suggestive epidemiology, she started empirical therapy for brucellosis with doxycycline and streptomycin. Subsequently, in the infection clinic, a diagnosis of $Q$ fever was confirmed and adjusted therapy. The patient completed 14 days of doxycycline treatment, with clinical improvement and no complications.

Comment: Patients with $\mathrm{Q}$ fever may present with a broad spectrum of disease manifestations: the absence of symptoms, mild to severe symptoms, as well as persistent localized disease. Due to the non-specificity of the signs and symptoms of $Q$ fever, laboratory diagnosis is essential for confirmation of clinical suspicion. For treatment, doxycycline is the first-line antibiotic for the treatment of this infection. This clinical case shows that the accessibility of primary health care currently promotes the first point of contact with the National Health Service and the role of the family doctor as responsible for articulation with other specialties.

Keywords: Zoonoses; Q fever; Primary health care. 